\title{
Aspirin, Vascular Disease and Cancer: 50 Years of Controversy and the Jury's Still Out!
}

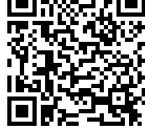

\author{
Peter Elwood* \\ Department of Inst of Population Medicine, Cardiff University, UK
}

Received: 㘹 May 26, 2018; Published: 海 June 11, 2018

*Corresponding author: Peter Elwood, Department of Inst of Population Medicine, Cardiff University, UK

\section{Aspirin and Vascular Disease}

The story of aspirin and vascular disease starts with John 0 Brien, a haematologist in Portsmouth in the 1960s, who reported that the ingestion of $150 \mathrm{mg}$ of aspirin substantially reduced the aggregation of platelets [1]. On the basis of this finding, and the assumption that the incidence of thrombosis would be reduced, O'Brien persuaded the UK Medical Research Council in 1968 to set up a randomised trial of aspirin [2]. Three hundred and three surgical patients in four UK hospitals were randomly given $600 \mathrm{mg}$ aspirin or a placebo once preoperatively and on five post-operative days. The outcome was deep vein thrombosis diagnosed by I125labelled fibrinogen. The conclusion, written presumably by Austin Heady the statistician on the team, was: 'aspirin administration has not even a marginal effect on the frequency of DVT'. This dismissal now appears rather confident in view of the later finding of clinically important reductions by aspirin in venous thrombosis and pulmonary embolism after surgery [3]. O Brien was convinced that venous thrombosis had been an inappropriate test of aspirin in the reduction of thrombosis but he failed to persuade MRC to conduct another trial. However, persuaded by work in the Welsh National School of Medicine in the 1960s on aspirin, platelet 'clumping' and 'infarctoid cardiopathy',[4-6] Archie Cochrane agreed that a trial of aspirin and vascular mortality be set up in South Wales. 1,400 postmyocardial infarction patients agreed to be randomised to $325 \mathrm{mg}$ aspirin orally per day the dose and frequency suggested for the trial by O'Brien. After two years, aspirin taking was associated with a $24 \%$ reduction in all-cause mortality [7]. Because of uncertainties in the clinical diagnosis of infarction, the protocol for the study had stated that all-cause mortality would be the sole outcome by which aspirin would be judged. The reduction failed to achieve significance at $\mathrm{P}>0.05$ and the report of the trial was therefore published under the heading 'For debate'. Under this same heading the BMJ published a remarkable observational study by Martin Vessey who had been on the steering Committee for the earlier MRC trial [2]. Together with Hershel Jick in Boston USA, Vessey looked for unknown adverse effects of medication by examining associations between drugs which had been taken by patients immediately prior to hospital admission, and the subsequent discharge diagnoses given to these patients. Their most notable finding in a series of such studies was a large negative association between the taking of aspirin by patients prior to hospital admission, and a discharge diagnosis of acute myocardial infarction (relative risk 0.53 ; 95\% CI 0.33, 0.84) [8]. Interpretation of this result was that aspirin either reduced the risk of infarction or increased in-hospital vascular mortality! Taken together with the results of the trial in South Wales a reduction in infarction by aspirin seemed the more likely.

By 1980 an additional five randomised trials of aspirin and vascular disease had been reported [9-13]. None of these achieved statistical significance at conventional levels of probability, and most colleagues therefore dismissed aspirin as of no clinical value - despite the clear evidence of consistency in the results of the trials. Sir Richard Peto however presented a meta-analysis of the six trials at the founding meeting of the Society for Clinical Trials in Philadelphia, and this was later published as an editorial in the Lancet in 1980. It showed a significant pooled reduction of $23 \%$ in secondary vascular disease mortality [14]. Cochrane later used this overview, one of the first in clinical medicine, to support his insistence that all the available evidence must be included in an evaluation of a clinical intervention, while Peto used the overview to warn of the dangers of under-powered trials. The overview clearly stimulated intense research activity and over the next twenty years 280 randomised trials of aspirin were reported. These were reviewed in a series of overviews by 'The Antiplatelet Trialists' Collaboration', led by Colin Baigent in Oxford [15-17] and they were followed by a remarkable overview based on individual patient data for 16 trials of secondary vascular protection with a total of 3,306 vascular events, and six primary trials with 3,554 vascular events [18]. Following these early overviews there was wide acceptance of aspirin prophylaxis for patients who had experienced a myocardial 
infarction, and gradually other groups of patients judged to be at high vascular risk were included in clinical recommendations for aspirin prophylaxis. Increasing concern however focused upon the risk-benefit balance of low-dose aspirin in primary care and attempts were made to define an age, or a level of vascular risk above which the risk of a gastrointestinal bleed attributable to aspirin might be acceptable. Thus, for example: aspirin should not be given to 'any individual with a calculated coronary disease event risk below $10 \%$ over 10 years' [19]. A commentary pointed out that 'the benefits and harms are ...finely balanced ...even in individuals estimated to be at high risk of experiencing cardiovascular events [20]. Another group wrote: 'any benefit of low-dose aspirin on risk of cardiovascuar disease in people aged 70 or over are offset by adverse events'. [21] All such judgements and advice were clearly based upon the numbers of bleeding episodes and assumed that a gastrointestinal bleed is as serious as a major vascular thrombotic event, or a vascular death. It was many years before this assumption was challenged. The role of aspirin in stroke became especially contentious. The report of 'The Antiplatelet Trialists' in 2002 [16] had reported a possible increase in stroke associated with aspirin and thereafter a particular concern focused upon aspirin and stroke. In an attempt to resolve the uncertainties, the journal Stoke published three contributions under an overall title: 'Controversies in Stroke'. The titles of each paper commenced: 'Aspirin should be first-line....' The first paper, by Charles Warlow, concluded: 'Aspirin still comes first' [22]. The second added the word 'Against' to the title [23]. The third added '...but watch this space' and referred to newer-generation antiplatelet and antithrombotic agents being developed [24]. Perhaps the last word on stroke should now be given to Rothwell, who, fourteen years later stated with Diener and others that 'Aspirin [is] the key intervention' and 'The considerable early benefit from aspirin warrants public education about selfadministration after possible TIA [transient ischaemic attack]' [25]. In 2005, perhaps also in an attempt to resolve controversy, the BMJ published a pair of invited papers 'For' and 'Against' under the title 'Aspirin for all over 50?' Both papers summarised the risks and benefits of aspirin. One stressed the likely numbers of bleeding events and concluded: 'it would be unwise to adopt such a policy, whatever age threshold is chosen [26]. The other focused upon the responsibility health professionals have to inform subjects and patients of the benefits and the risks of aspirin, and the duty to respect the values and the judgements of their patient [27].

Controversy continued and in retrospect it is unfortunate that opportunities were not taken in some of the trials to address some of the contentious issues by separate randomisation. Thus, different strategies to reduce the risk of bleeding could have been compared. Evidence suggesting that the vascular benefits of aspirin may be greater if the drug is taken in the evening rather than in the morning $[28,29]$ could have been evaluated. Other evidence suggested that 'excellent' adherence to aspirin taking is associated with much greater protection than 'poor' adherence [30]. It is regrettable that these and other issues were not taken up and tested by separate randomisation within the trials. In 2005, 25 years after Peto's overview, a commentary in the British Medical Journal carried the title: 'Aspirin to prevent cardiovascular disease the jury's still out' [31]. This was followed immediately by a challenging letter: 'The debate about aspirin has consumed the medical profession for over 30 years, yet almost no public participation or consultation has occurred..... a citizens' jury should consider aspirin prophylaxis' [32]. The jury system was brought to England by William I in 1066 and trial by jury became the right of every free person, to protect the rights of the individual and to prevent intrusive external judgements by churchmen and others in authority. The Citizens' Jury, which is closely modelled on the legal system, attempts to ascertain views from the public on how priorities for healthcare should be set, without intrusive judgements by doctors and others with vested interests and biases.

A Citizen's Jury was therefore held in Cardiff in October 2006 under the title: 'My Health whose responsibility?' [33] Sixteen members of the general public, the 'jurors', were addressed by expert witnesses, including clinicians, a general practitioner, an epidemiologist, a pharmacologist, a psychologist and a public health practitioner. These gave evidence to the jury and were freely questioned and challenged by the jurors. After three days of presentations and discussion the jurors wrote their report. There was unanimity in a verdict that while treatment is rightly delegated to healthcare professionals, prevention is the responsibility of the individual subject. There was agreement that patients and members of the general public should be presented with the evidence on preventive strategies.... and to this the jurors added: 'even before there is agreement between doctors'.

\section{Aspirin and the Prevention of Cancer}

This interaction with the public led the organisers to conduct an extensive review of evidence on aspirin and cancer [34] a topic which had been of particular interest to the participants in the Citizens' Jury. Relevant literature on aspirin and cancer goes back to Gasic and others [35-37] who, in a series of animal studies showed that thrombocytopenia is associated with a reduction in metastases, and that experimentally-induced metastatic spread is reduced by aspirin. They concluded that these findings 'strongly support the role of platelet aggregation and the platelet release reaction in metastasis'. It seems however that all this was ignored until a serendipitous finding in a retrospective study indicated a strong negative association between colon cancer incidence and taking aspirin [38]. The review published in 1988 included relevant evidence on salicylates in botanical studies, aspirin in animal studies, studies of cellular mechanisms, Mendelian Randomisation studies and human observational studies [34]. The authors concluded however, that because of ethical and other difficulties with the use of placebos, clinical decisions about the use of aspirin in the reduction of cancer would have to be based on evidence other than that from randomised trials. How wrong this conclusion was! Almost simultaneously, a number of long-term follow-up studies of 
early trials which had originally been conducted to examine aspirin and vascular disease were conducted and data on cancer incidence and mortality obtained [39-42]. These studies consistently detected a reduction in the incidence and the mortality of cancer in patients who had, up to twenty years earlier, been randomised to aspirin for vascular protection. A number of criticisms were quickly made. Thus: the decisions to investigate cancer incidence and mortality had been made post hoc; the follow-up in each study was extended far beyond randomisation, and in most of the studies blindness as to aspirin or placebo had been abandoned on completion of the original trial. Furthermore, two very similar follow-up studies of randomised cohorts in the USA, the Women's Health Study and the Physician's Health Study showed no evidence of any reduction in cancer in the subjects who had originally been randomised to aspirin.

Meanwhile, an interest developed in the use of aspirin prophylaxis alongside colorectal cancer screening. [43] The effectiveness of screening is best in the distal colon, while aspirin appears to have its effect mainly in the proximal colon, and the overall benefit, and risks, of the two procedures appear to be fairly comparable [44]. This, combined with a low acceptance of screening, makes a combined strategy highly attractive. Others however judged the benefit of aspirin to be at best modest, and claimed that the addition of aspirin prophylaxis to colorectal screening would unreasonably increase the cost of prevention [45]. Most recently there has been increasing interest and controversy in aspirin as an additional treatment of cancer. In fact, during the 50 years since the early predictions by Gasic and others details of the involvement of platelets and the vessel wall in the metastatic spread of cancer has been well worked out, making benefit from aspirin on active cancer a most reasonable expectation [45]. In 2016 a systematic review of studies of aspirin taken by patients with cancer was reported [46]. Forty-two studies were identified and a meta-analysis of these gave a pooled estimate of a reduction in the cancer specific mortality of colon, breast and prostate cancer of about $25 \%$ and a pooled estimate of a reduction in metastatic spread of about $25 \%$. Both these estimates were significant, but showed marked heterogeneity. The authors however judged the evidence sufficient to recommend that: 'physicians should engage with patients in a presentation and discussion of aspirin as an additional treatment.' This was quickly followed by an 'Interpretation' which pointed out that the evidence on aspirin and the treatment of cancer was almost entirely observational and because of possible bias: 'Current evidence is not sufficient.... [and] the use of aspirin would be a bridge too far' [47].

\section{Aspirin and Bleeding}

The issue that has generated, and continues to generate by far the most controversy, is gastrointestinal (GI) bleeding from aspirin. Aspirin apart, within the general adult population GI bleeding occurs in about one person in every 1,000 each year, with about $1 \%$ of the bleeds being fatal. Low-dose aspirin is responsible for about a $60 \%$ increase, which means that amongst patients taking low-dose aspirin who present with a GI bleed, aspirin is likely to be responsible for only about one in every three of these bleeds. An iatrogenic event is however especially unfortunate in preventive procedures recommended to healthy subjects, and to a healthy subject a stomach bleed must be a crisis. And yet, stomach bleeds are hardly of the same seriousness, and appears not to have the same long-term consequences as a vascular disease event or a cancer. In June 2016 Reuters issued a press release stating: 'daily aspirin causes 3,000 deaths from bleeding in Britain every year', [48] and this was taken up and widely publicised across the media. It was however 'fake news'! The report upon which the claim was based described bleeding in patients who had experienced a heart attack or a stroke, all of whom (93-97\%) were taking aspirin [49] There were no control patients not taking aspirin, and so no valid estimate of the independent contribution of aspirin to the fatal bleeds can be made. Estimates of the risk of fatal bleeding had in fact already been reported in a number of earlier overviews and while all the studies confirm an increase in total GI bleeding, there appears to be little evidence of an increase in fatal GI bleeding. In fact, evidence commencing in one of the early reports of the Antithrombotic Trialists' Collaboration[17] and a number of subsequent reviews suggests that the frequency of fatal gastrointestinal bleeding may be reduced in subjects taking aspirin [50-55]. The extent to which lowdose aspirin is truly responsible for GI bleeds, and the frequency with which the taking of aspirin simply increases bleeding from a pre-existing ulcer or gastric infection has not been adequately investigated. Consistent with an effect upon pre-existing disease is the finding that most of the GI bleeds in subjects taking aspirin appear to occur early, most within the first month of taking aspirin, [56] and most of the fatal GI bleeds occur very shortly after aspirin taking starts and the frequency of death thereafter falls rapidly. [57] All this would seem to be consistent with the presence of untreated gastric pathology at the time the aspirin treatment had commenced. Low-dose aspirin has also been shown to be responsible for an additional one or two cerebral bleeds per year in every 10,000 subjects [58]. About one third of the bleeds are fatal, and most of the patients who survive have physical and mental impairment $[59,60]$. All this ignores the possible reduction of the risks of bleeding. Proton pump inhibitor drugs (PPIs) provide a high level of protection from intestinal bleeding whatever its aetiology, $[61,62]$ and formulae to assist in judging the risk of a gastrointestinal bleed in a subject are available $[63,64]$. Hypertension is the main factor in haemorrhagic stroke, [17] and the Hypertension Optimal Treatment (HOT) trial of aspirin showed that if hypertension is adequately treated the additional cerebral haemorrhage attributable to aspirin is reduced and perhaps eliminated [65].

\section{Further Research}

Certainty is elusive and new research is always valuable, whatever the topic. Several major trials of aspirin (ASCEND, ASPREE and ARRIVE) are likely to be reported soon [66]. Whether or not 
these resolve the controversy will be of interest - but controversy on whose part, our esteemed colleagues, or the public we serve?

\section{Conclusion}

a) The imaginary jury of the BMJ [31] has been 'out' for a further 13 years. It is now a 'hung' jury and should be dismissed.

b) The verdicts of a Citizen's Jury [33] are still valid.

c) Evidence from the expected new trials will rightly be presented by experts in technical and statistical terms, but every effort should be made to present the evidence on risks and benefits in terms understandable by the public, and wide and repeated involvement of the public in conferences, discussions, public meetings, focus groups and Citizens' Juries on prophylaxis should be stimulated.

d) Low-dose aspirin, and indeed every drug for which prophylaxis is claimed, should be presented within the context of a healthy lifestyle: 'better than any pill, no cost and no side effects!'[67-70].

\section{References}

1. O Brien JR (1968) Effects of salicylates on platelet stickiness. Lancet 291(7546): 779-783

2. Butterfield WJH, Hicks BH, Ambler AR, Barkhan P, Gollop G, et al. (1972) Effect of aspirin on post-operative venous thrombosis. Lancet 300: 441445.

3. (2000) Pulmonary Prevention (PEP) Trial Collaborative Group Prevention of pulmonary embolism and deep vein thrombosis with low dose aspirin: Pulmonary Embolism Prevention (PEP) trial. Lancet 355(9212): 1295-1302.

4. Hughes A, Tonks RS (1965) Platelets, magnesium and myocardial infarction. Lancet 1044-1046.

5. Davies DPT, Hughes A, Tonks RS (1968) Salicylate and erythrocyte metabolism. Brit J Pharm and Chemotherapy 33: 206-209.

6. Davies HTP, Hughes A, Tonks RS (1968) Experimental and clinical lung and heart lesions resulting from intravascular platelet clumping and some factors in their prevention. Proceedings of the 3rd International Pharmacological Meeting. S Paulo, Brazil 1966. In: Drugs in relation to blood coagulation, haemostasis and thrombosis. Pergamon Press. Oxford and New York.

7. Elwood PC, Cochrane AL, Burr ML, Sweetnam PM, Williams G, et al. (1974) A randomized controlled trial of acetyl Salicylic Acid in the secondary prevention of mortality from myocardial infarction. Br Med J 1(5905): 436-440.

8. (1974) Boston Collaborative Drug Surveillance Group. Regular aspirin intake and acute myocardial infarction. BMJ 1: 440-443.

9. Coronary Drug Project (CDP) (1976) Aspirin in coronary heart disease. J Chron Dis 29: 625-642.

10. Elwood PC, Sweetnam PM (1979) Aspirin and secondary mortality after myocardial infarction. Lancet 2: 1313-1315.

11. Breddin K, Loew D, Lechner K, Uberla K, Walter E (1980) Secondary prevention of myocardial infarction: a comparison of acetyl salicylic acid, placebo and phenprocoumen, Haemostasis 9(6): 325-344.

12. (1980) Aspirin myocardial Infarction Study Research Group (AMIS). A randomised controlled trial in persons recovered from myocardial infarction. JAMA 243(7): 661-669.
13. (1980) Persantin Aspirin Reinfarction study (PARIS) group. Persantin and aspirin in coronary heart disease. Circulation 62(3): 449-461.

14. Peto R (1980) Aspirin after myocardial infarction. Lancet 1(8179): 1172-1173.

15. Antithrombotic Trialists Collaboration (1994) Collaborative overview of randomized trial of prevention of death, myocardial infarction and stroke by prolonged antiplatelet therapy in various categories of patients. BMJ 308(6921): 81-106

16. Antithrombotic Trialists Collaboration (2002) Collaborative metaanalysis of randomized trial of antiplatelet therapy for prevention of death, myocardial infarction and stroke in high risk patients. BMJ 324(7329): 71-86.

17. Antithrombotic Trialists Collaboration (2009) Aspirin in the primary and secondary prevention of vascular disease: collaborative metaanalysis of individual participant data from randomized trials. Lancet 373(9678): 1849-1860.

18. Antithrombotic Trialists Collaboration (2009) Aspirin in the primary and secondary prevention of vascular disease: collaborative metaanalysis of individual participant data from randomised trials. Lancet 373(9678): 1849-1860.

19. Sanmuganathan PS, Ghanhramani P, Jackson PR, Wallis EJ, Ramsay LE (2001) primary prevention of coronary heart disease: safety and absolute benefit related to coronary risk derived from meta-analysis of randomised Aspirin for trials. Heart 85(3): 265-271.

20. ISIS-2 (1988) Second International Study of Infarct Survival Collaborative Group. Randomised trial of intravenous streptokinase, oral aspirin, both and neither among 17,187 cases of suspected acute myocardial infarction: ISIS-2. Lancet 2(8607): 349-360.

21. Nelson MR, Liew D, Bertram M, Vos T (2005) Epidemiological modelling of routine use of low-dose aspirin for the primary prevention of coronary heart disease and stroke in those aged 70 years and over. BM] 330(7503): 1306-1308.

22. Warlow C (2002) Controversies in stroke: Aspirin should be first-line antiplatelet therapy in the secondary prevention of stroke. Stroke 33: 2137-2138.

23. Diener HC (2002) Aspirin therapy should be first-line treatment in secondary prevention against. Stroke 33: 2138-2139.

24. Donnan GA, Davis SM (2002) Aspirin therapy should be first line Probably, but watch this space. Stroke 33: 2139-3110.

25. Rothwell PM, Agra A, Chen Z, Diener HC Norrving B, et al. (2016) Effects of aspirin on risk and severity of early recurrent stroke after transient ischaemic attack and ischaemic stroke: time-course analysis of randomised trials. Lancet 388: 365-375.

26. Baigent C (2005) Aspirin for all over 50? Against. Brit Med J 330: 1442 1443.

27. Elwood P, Morgan G, Brown G, Pickering J (2005) Aspirin for all over 50 ? BMJ 330(7505): 1440-1441.

28. Toffler GH, Brezinshi DA, Schaffer AI (1987) Concurrent morning increase in platelet aggregability and the risk of myocardial infarction and sudden cardiac death. N Engl J Med 316: 1514-1518.

29. Kriszbacher I, Koppan M, Bodis J (2004) Aspirin for stroke prevention taken in the evening?. Stroke 35: 2760-2762.

30. Glynn RJ, Buring JE, Manson JE, LaMotte F, Hennekens CH (1994) Adherence to aspirin in the prevention of myocardial infarction: The Physicians Health Study. Arch Intern Med 154(23): 2649-2657.

31. (2005) Editorial. Aspirin to prevent cardiovascular disease in elderly people: the jury's still out. Brit Med J 330(7503). 
32. Iredale RT (2005) Citizen jury should consider aspirin prophylaxis. BM 331(7509): 160.

33. Elwood PC, Longley M (2010) My health whose responsibility: a jury decides. J Epidemiol Comm Hlth 64(9): 761-764.

34. Elwood PC, Gallacher AM, Duthie GG, Mur LAJ, Morgan G (2009) Aspirin, salicylates and cancer. Lancet 373(9671): 1301-1309.

35. Terranova T, Chiossone F (1952) Coagulation factors in the attachment of neoplastic cells released into the circulation. Boll Soc Ital Biol Sper 28(6): 1224-1225.

36. Gasic G, Gasic T, Stewart CC (1968) Antimetastatic effects associated with platelet reduction. Proc Natl Acad Sci, USA 61(1): 46-52.

37. Gasic GJ, Gasic TB, Galanti N, Johnson T, Murphy S (1973) Platelet-tumorcell interactions in mice. The role of platelets in the spread of malignant disease. Int J Cancer 11(3): 704-708.

38. Kune GA, Kune S, Watson LF (1988) Colorectal cancer risk, chronic illnesses, operations and medications: case-control results from the Melbourne Colorectal Cancer Study. Cancer Res 48(15): 4399-4404.

39. Rothwell PM, Wilson M, Elwin CE, Norrving B, Algra A, et al. (2010) Longterm effect of aspirin on colorectal cancer incidence and mortality: 20 year follow-up of five randomised trials. Lancet 376(9754): 1741-1750.

40. Rothwell PM, Fowkes FG, Belch JF, Ogawa H, Warlow CP, et al. Effect of daily aspirin on long-term risk of death due to cancer: analysis of individual patient data from randomised trials. Lancet 2011 327(9759): 31-41.

41. Rothwell PM, Price JF, Fowkes GR, Zanchetti A, Roncaglioni MC, et al. (2012) Short-term effects of daily aspirin on cancer incidence, mortality and non-vascular death: analysis of the time course of risks and benefits in 51 randomised controlled trials. Lancet 379(9826): 1602-1612.

42. Rothwell PM, Wilson M, Price JF, Belch JF, Meade TW, et al (2012) Effect of daily aspirin on risk of cancer metastasis: a study of incident cancers during randomised controlled trials. Lancet 379(9826): 1591-1601.

43. Elwood PC, Steward WP, Galante J (2013) Colorectal cancer prevention: screening and the role of aspirin. Colorectal Cancer 2(5): 429-439.

44. Emilsson L, Holme, Bretthauer M, Cook NR, Buring JE et al. (2017) Systematic review with meta-analysis: the comparative effectiveness of aspirin vs. screening for colorectal cancer prevention. Aliment Pharmacol Ther 45(2): 193-204.

45. Imperiali TF (2003) Aspirin and the prevention of colorectal cancer. NEJM 348: 879-880.

46. Gay LJ, Felding Habermann B (2011) Contribution of platelets to tumour metastasis. Nat Rev Cancer 11(2): 123-134.

47. Frouws MA, van Herk Sukel MPP, Maas HA, Van de Velde CJH, Portielje JEA, et al (2017) The mortality reducing effect of aspirin in colorectal cancer patients: interpreting the evidence. Cancer Cancer Treat Rev 55: 120-127.

48. http://www.newsweek.com/aspirin-every-day-increases-risk-seriousbleeding-625364.

49. LiL, Geraghty OC, Mehta Z, Rothwell PM (2017) Age specific risks, severity, time course and outcome of bleeding on long-term antiplatelet treatment after vascular events: a population-based cohort study. Lancet 390(10093): 490-499.

50. Lanas A, Fuentes J, Benito R, Serrano P, Bajador E, et al. (2002) Helicobacter pylori increases the risk of upper gastrointestinal bleeding in patients taking low-dose aspirin. Aliment Pharmacol Ther 16: 779786.

51. Morgan G (2009) Aspirin for primary prevention of vascular events. Public Health 123(12): 787-788.
52. Mc Quaid KR, Laine L (2006) Systematic review and meta-analysis of adverse events of low-dose aspirin and clopidogrel in randomised controlled trials. Amer J Med 119: 624-638.

53. Wu C, Alotaibi GS, Alsaleh K, Linkins LA, McMurtry MS (2015) Casefatality of recurrent venous thromboembolism and major bleeding associated with aspirin, warfarin, and direct oral anticoagulants for secondary prevention. Thromb Res 135(2): 243-248.

54. Wehbeh A, Tamim HM, Abu Daya H, Abou Mrad R, Badreddine RJ, et al. (2015) Aspirin has a protective effect against adverse outcomes in patients with nonvarical upper gastrointestinal bleeding. Dig Dis Sci 60(7): 2077-2087.

55. Elwood PC, Morgan G, Galante J, Chia JW, Dolwani S, et al (2016) Systematic review and meta-analysis of randomised trials to ascertain fatal gastrointestinal bleeding events attributable to preventive lowdose aspirin: no evidence of increased risk. PLoS One 11(11): e0166166.

56. Garcia Rodriguez LA, Hermandez S, De Abajo J (2001) Association between aspirin and upper gastrointestinal complications: systematic review of epidemiologic studies. Br J Clin Pharmacol 52: 563-571.

57. Hochholzer W, Wiviott SD, Antman EM, Contant CF, Guo J, et al. (2011) Predictors of bleeding and time dependence of association of bleeding with mortality. Circulation 123(23): 2681-2689.

58. Simona Sacco, Carmine Marini, Danilo Toni, Luigi Olivieri (2009) Antonio Carolei Incidence and 10-Year Survival of Intracerebral Hemorrhage in a Population-Based Registry. Stroke 40: 394-399.

59. Nilsson OG, Lindgren A, Ståhl N, Brandt L, Säveland H (2000) Incidence of intracerebral and subarachnoid haemorrhage in southern Sweden. J Neurol Neurosurg Psychiatry 69(5): 601-607.

60. Abraham NS, Hlatky MA, Antman EM, Bhatt DL, Bjorkman DJ, et al. (2010) ACCF/ACG/AHA Expert Consensus Document on the concomitant use of proton pump inhibitors and thienopyridines: a focused update of the ACCF/ACG/AHA 2008 expert consensus document on reducing the gastrointestinal risks of antiplatelet therapy and NSAID use: a report of the American College of Cardiology Foundation Task Force on Expert Consensus Documents. Circulation 122(24): 2619-2633.

61. Mo C, Sun G, Lu ML, Zhang L, Wang YZ, et al. (2015) Proton pump inhibitors in prevention of low-dose aspirin-associated upper gastrointestinal injuries. World Journal of Gastroenterology 21(17): 5382-5392.

62. Lanas A, Polo Tomas M, Casado Arroyo R (2013) The aspirin cardiovascular/gastrointestinal risk calculator--a tool to aid clinicians in practice. Aliment Pharmacol Ther 37(7): 738-748.

63. Collins GS, Reitsma JB, Altman DG, Moons KG (2015) Transparent reporting of a multivariable prediction model for individual prognosis or diagnosis (TRIPOD): the TRIPOD statement. British Medical Journal 350: g7594.

64. Hansson L, Zanchetti A, Carruthers SG, Dahlof B, Elmfeldt D, et al (1998) Effects of intensive blood-pressure lowering and low-dose aspirin in patients with hypertension: principal results of the Hypertension Optimal Treatment (HOT) trial. HOT study group. Lancet 351(9118): $1755-1762$.

65. Sokol DK (2015) Update on the UK law on consent. British Medical Journal 350: h1481.

66. Baigent C (2016) Aspirin for Disease Prevention: Public Policy or Personal Choice?. Annals of Internal Medicine 164(12): 21.

67. Elwood PC, Galante J, Pickering JE, Palmer S, Bayer A, et al. (2013) Healthy Lifestyles Reduce the Incidence of Chronic Diseases and Dementia: Evidence from the Caerphilly Cohort Study. PLoS One 8(12): e81877.

68. Elwood PC, Whitmarsh A, Gallacher J, Bayer A, Adams R, et al. (2018) Healthy living and cancer: evidence from UK Biobank. Ecancermedicalscience 12: 792. 
69. (1988) Antithrombotic Trialists Collaboration. Secondary prevention of vascular disease by prolonged antiplatelet treatment. BMJ 296(6618): 320-331.
70. Elwood PC, Morgan G, Pickering JE, Julieta Galante, Alison L Weightman, et al (2016) Aspirin in the treatment of cancer: reductions in metastatic spread and in mortality: a systematic review and meta-analysis of published studies. Plos One.

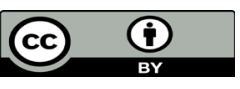

This work is licensed under Creative Commons Attribution 4.0 License

To Submit Your Article Click Here:

Submit Article

DOI: $10.32474 /$ OAJOM.2018.02.000126

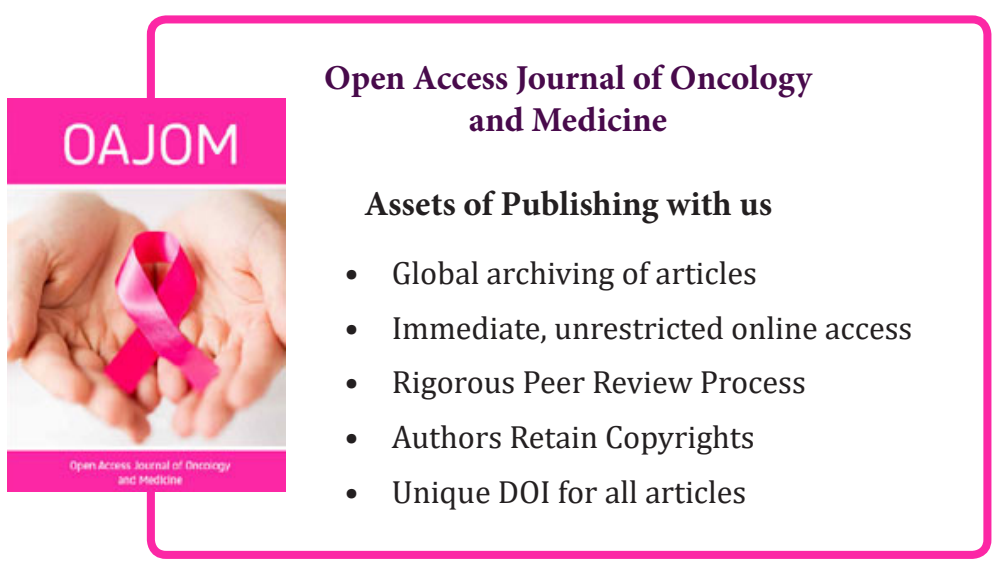

